\title{
Histopathological and Ultrastructural Studies on the Protective Effect of Daidzein and Vitamin C Against Gamma Irradiation- Induced Kidney Alterations in Albino Rats
}

\author{
Original \\ Article \\ Marwa Salah ${ }^{1}$, Manal Abdul-Hamid ${ }^{1}$, Saeed Mohamed Soliman ${ }^{2}$ and \\ Hadeer Osman ${ }^{1}$
}

${ }^{1}$ Department of Zoology, Faculty of Science, Beni-Suef University, Beni Suef, Egypt

${ }^{2}$ National Center for Radiation Research and Technology (NCRRT) Atomic Energy Authority

\begin{abstract}
Introduction: Radiotherapy is an important therapeutic manner of a wide range of tumors. Its side effects on normal cells limit the efficiency of therapy.

Aim of the work: To evaluate the protective role of daidzein and/or vitamin $\mathrm{C}$ against biochemical, histopathological and ultrastructural changes in male albino rats exposed to gamma radiation ( $\gamma$-radiation).

Materials and Methods: The whole-body exposed to 8 GY $\gamma$-radiation. Daidzein was given to rats at a concentration of 63 $\mathrm{mg} / \mathrm{kg} \mathrm{b}$.wt./day for 7 days before irradiation and 7 days during exposure. Whereas vitamin $\mathrm{C}$ was ingested at a concentration of $5 \mathrm{mg} / \mathrm{kg}$ b.wt. /day for 7 days before irradiation and 7 days during exposure. Animals were sacrificed on the 1st day post the irradiation dose. Blood samples were collected for biochemical determination of uric acid, urea, and creatinine. Lipid peroxides (TBARS) concentration and the activities of superoxide dismutase (SOD), catalase (CAT), and glutathione peroxidase (GPx) were also measured. Samples from the kidney were processed for light and electron microscopy.

Results: Irradiation induced significant elevation in uric acid, urea, creatinine and TBARS. These changes were accompanied by significant decrease in antioxidant status (SOD, CAT, and GPx). Also, the histological and ultrastructural investigation displayed remarkable changes in kidney tissue. Daidzein and /or vitamin C reduced the kidney damage induced by irradiation; this was showed by declined levels of creatinine, urea and uric acid, in addition to increased CAT, GPx, and SOD activities. The histopathological structure and ultrastructural alternations were also improved. The radioprotection index for the combination of daidzein and vitamin $\mathrm{C}$ was found to be more than daidzein or vitamin $\mathrm{C}$ separately.

Conclusion: Daidzein and vitamin $\mathrm{C}$ might modulate radiation damages to kidney by boosting the antioxidant capacity and attenuating oxidative injury.
\end{abstract}

Received: 08 August 2019, Accepted: 05 October 2019

Key Words: Daidzein, gamma radiation, histopathology, oxidative stress, ultrastructural study, Vitamin C.

Corresponding Author: Manal Abdul-Hamid, PhD, Department of Zoology, Faculty of Science, Beni-Suef University, Beni Suef, Egypt, Tel.: +20 1005168380,E-mail: medo_bio@yahoo.com

ISSN: 1110-0559, Vol. 43, No.2

\section{INTRODUCTION}

Radiotherapy is an important therapeutic manner of a wide range of tumors. Its side effects on normal cells limit the efficiency of therapy. Absorption of Ionizing radiation (IR) by the cells can directly disturb atomic structures, creating chemical and biological alterations. Indirectly, it can act through water radiolysis, thus creating reactive oxygen species (ROS) which cause oxidative injury to vital biomolecules like DNA, proteins, and lipids ${ }^{[1]}$. Production of free radicals caused oxidative stress, which is connected with various degenerative diseases comprising heart attack, cancers, arthritis, atherosclerosis, asthma, kidney, and liver damage $^{[2]}$. Both effects of radiation (direct and indirect) stimulate a chain of biochemical and molecular actions that repair the injury or end in permanent physiological modifications or cell death ${ }^{[3]}$.
The protection against ROS is directed by intracellular systems like reducing agents as vitamin $\mathrm{C}$ or antioxidant enzymes ${ }^{[4]}$. The reduced capacity to hunt free radicals and ROS as a result of reduced cellular levels of antioxidant defense systems or more free radical generation in liver, brain, kidney, and other organs ${ }^{[5]}$. The use of antioxidants has great attention since it has been detected that the protection of normal cells may offer an elevation in tumor control by increasing the dose of radiation ${ }^{[6]}$.

Vitamin $\mathrm{C}$ has been recorded to be an operative antioxidant and free radical scavenger and decrease the injury to DNA and biological membranes induced by free radicals ${ }^{[7]}$. It is a free radical scavenger and has been revealed to protect numerous biological systems against radiation. The radio-protective effect of ascorbic acid appears to be due to its interactions with free radicals induced by radiation ${ }^{[8]}$. 
Vitamin C pre-treatment decrease lipid peroxidation caused by radiation ${ }^{[9]}$. It protected mice from radiation-induced diseases, reduced mortality and enhanced healing of wounds induced by whole-body gamma rays $(\gamma \text { rays })^{[10]}$.

Flavonoids, broadly dispersed in vegetable pigments, have received great attention because of their pharmacological properties. They have an anti-inflammatory, anti-tumor, antiviral, and anti-allergic effect. The pharmacological activities of bioflavonoids have been attributed to their free radical scavenging activity and iron-chelating ability ${ }^{[1]]}$.

Ingesting of isoflavones, like daidzein, has been revealed protection against oxidative injury in human and animals ${ }^{[12]}$. Daidzein has been revealed to have an antioxidant effect in different tissues ${ }^{[13]}$. Daidzein was given intraperitoneally rather than orally ${ }^{[14]}$. Daidzein amount has been revealed to increase glutathione (GSH) levels ${ }^{[15]}$. Another finding in a study reported that daidzein reduced liver Malondialdehyde (MDA) level in control animals by indirect mechanisms ${ }^{[16]}$. Also, it may act as a free radical scavenger to end lipid peroxidation, therefore the chemical construction of daidzein favors the donation of its hydrogen atoms to the superoxide anions in vitro, thus preventing lipid peroxidation ${ }^{[17]}$.

Consequently, the objective of the current study is to assess the probable defensive effect of two antioxidants, namely, vitamin $\mathrm{C}$ and daidzein, against kidney injury caused by $\gamma$-radiation in rats. This was achieved by assessing some biochemical parameters together with light and ultrastructural examinations of the kidney in male albino rats.

\section{MATERIALS AND METHODS}

Adult male albino rats, weighing 120-140 gm, were obtained from the Egyptian Organization for Biological Products and Vaccines. The rats were kept under observation for about two weeks, before the beginning of the trial, to avoid any intercurrent infection and to adapt the laboratory environments. The rats were housed in good aerated metal cages at normal atmospheric temperature $\left(25 \pm 5^{\circ} \mathrm{c}\right)$ and normal daily $12 \mathrm{~h}$ dark and $12 \mathrm{~h}$ light cycle. Experiments were done as per internationally followed ethical standards and according to the Guide for the Care and Use of Laboratory Animals of the National Institutes of Health. The rats were not treated with insecticides or antibiotics and fed standard commercials diet (ATMID Company, Giza, Egypt) and tap water ad libitum.

\section{Radiation Processing}

Gamma Cell 40 is a cesium 137 irradiation unit, belonging to the National Center for Radiation Research and Technology (NCRRT), at Cairo, Egypt, manufactured by Atomic energy of Canada Limited and designed for use in an unshielded room. The unit provides a mean for a uniform $\gamma$-irradiation of small animals or biological samples while providing broad protection for working person. A cesium-137 encapsulated source is kept in each of two cylindrical sliding drawers, one below and one above the sample cavity.
The source drawers are moved from the shielded position to the irradiation position by a pneumatic cylinder. A plastic sample tray supported for use in sample cavity is available with the unit. The internal dimensions of the tray are $30.5 \mathrm{~cm}$ diameter by $0.5 \mathrm{~cm}$ depth and have ventilation holes in its side. The dose rate of experimentation was $1.3 \mathrm{r} / \mathrm{s}$.

\section{Treatment}

\section{Preparation of Daidzein for Oral Administration}

Daidzein was purchased from Arkopharma, U.K. It was administered to rats via stomach tube at a concentration of $63 \mathrm{mg} / \mathrm{kg} \mathrm{b}$. wt./day according to El Ashry et al. ${ }^{[18]}$. The daily administration dose was contained in distilled water.

\section{Preparation of Vitamin C for Oral Administration}

Vitamin C was obtained from Memphis-Co for pharm. Chem. Ind., Cairo. It was supplied to certain groups of animals at a dose of $5 \mathrm{mg} / \mathrm{kg} \mathrm{b}$. wt./day according to $\mathrm{Abu}$ Simmo et al.$^{[19]}$ by intragastric gavages.

\section{Radiation Dose}

The whole body were exposed to $\gamma$-irradiated with 8 Gy administrated 2 Gy day every other day ${ }^{[18]}$.

\section{Experimental Design}

Rats were divided into seven groups under investigation, (each of ten rats):

Group 1: Control, non-irradiated or treated normal rats of this group received $1 \mathrm{ml}$ of water through gastric intubations for 14 consecutive days.

Group 2: Daidzein, non-irradiated but rats of this group received daidzein $(63 \mathrm{mg} / \mathrm{kg}$ b.wt./ day) through gastric intubations for 14 consecutive days.

Group 3: Vitamin C, non-irradiated but rats of this group received vitamin $C(5 \mathrm{mg} / \mathrm{kg}$ b.wt./ day) through gastric intubations for 14 consecutive days.

Group 4: Irradiated-group, rats of this group, whole-body exposed to fractioned $\gamma$ - irradiation (2 GY increment, day every other day) up to the total dose of 8 GY (i.e. 2 GYx4).

Group 5: Daidzein Irradiated-group, rats of this group protected with daidzein as they received $63 \mathrm{mg}$ daidzein $/ \mathrm{kg}$ b.wt. /day through gastric intubation for 7 consecutive days, before receiving the radiation dose and 7 days with delivering the radiation fractions $(2 \mathrm{GY} \times 4)$.

Group 6: Vitamin C Irradiated-group, rats of this group protected with vitamin $\mathrm{C}$ as they received $5 \mathrm{mg}$ vitamin $\mathrm{C} / \mathrm{kg} \mathrm{b}$.wt. /day through gastric intubation for 7 consecutive days, before receiving the radiation dose and 7 days with delivering the radiation fractions $(2 \mathrm{GY} \times 4)$.

Group 7: Mixture (Daidzein and Vitamin C) Irradiated group, rats of this group protected with both daidzein and vitamin $\mathrm{C}$ as they received a mixture of $63 \mathrm{mg}$ daidzein $/ \mathrm{kg}$ b.wt./day and $5 \mathrm{mg} / \mathrm{kg}$ b.wt./day vitamin $\mathrm{C}$ through 
gastric intubation for 7 consecutive days, before receiving the radiation dose and 7 days with delivering the radiation fractions $(2 \mathrm{GYX} 4)$.

\section{Sampling \\ Blood Samples}

At the end of the experiment, animals were subjected to diethyl ether anesthesia. Blood samples were collected, left for $1 \mathrm{hr}$ at room temperature and then centrifuged at $3000 \mathrm{rpm}$ for 15 minutes to separate serum which was kept at $-20^{\circ} \mathrm{c}$ till used for biochemical determination of Uric acid ${ }^{[20]}$, urea ${ }^{[21]}$ and creatinine ${ }^{[22]}$. The concentration of lipid peroxides (TBARS) ${ }^{[23]}$ and the activities of superoxide dismutase $\mathrm{SOD}^{[24]}$, catalase $(\mathrm{CAT})^{[25]}$ and the concentration of glutathione peroxidase $(\mathrm{GPx})^{[26]}$ were determined in blood serum.

\section{Histological Preparations}

\section{Preparation of Paraffin Sections}

At the end of the experiment, Rats were anesthetized by light diethyl ether and dissected to remove the right kidney. Small tissue specimens $(3 \mathrm{~mm} 3)$ were fixed in neutral buffered formalin (10\%) for 24 hours. Tissues were washed to eliminate the excess of formalin and then dehydrated by using ethanol (70-100\%) for 45 minutes each. After that the tissues were put in two changes of absolute ethanol (30 minutes each). Tissues were then cleared in two changes of xylol (30 minutes each). This was followed by impregnation in paraplast plus at $60^{\circ} \mathrm{C}$ (three changes) for three hours and then embedded in paraplast plus. Sections $(4-5 \mu \mathrm{m}$ thick) were prepared with a microtome and stained with haematoxylin and eosin for histopathological examination ${ }^{[27]}$.

\section{Ultrastructural Preparations}

Samples from the right kidney (1 mm3 thick) were immediately fixed in fresh 3\% glutaraldehyde-formaldehyde at $4^{\circ} \mathrm{C}$ for $18-24$ hours. The tissues were washed in phosphate buffer ( $\mathrm{pH}$ 7.4) and then postfixed in isotonic $1 \%$ osmium tetroxide at $4^{\circ} \mathrm{C}$ for one hour ${ }^{[28]}$. Dehydration in ascending grade of alcohol was carried out. Samples were then moved to propylene oxide solution 2 times (10 minutes each) and embedded in epoxy resin. Semithin sections $(1.0 \mu \mathrm{m}$ thick) were obtained and stained with toluidine blue and investigated by light microscope to select the area of interest. Ultrathin sections were prepared and stained with uranyl acetate and lead citrate ${ }^{[29]}$ finally investigated with a Joel CX 100 Transmission Electron Microscope operated at an accelerating voltage $60 \mathrm{KV}$.

\section{Statistical Analysis}

The statistical package was used for the Social Sciences SPSS for WINDOWS, version 20.0; SPSS Inc, Chicago ${ }^{[30]}$. The data were represented as mean \pm standard error $(\mathrm{M} \pm \mathrm{SE})$. All statistical comparisons were made by using one-way ANOVA test then followed by Duncan's multiple range test post-hoc analysis values. $P>0.05$ were considered statistically non-significant, the values of $P<0.05$ were considered as statistically significant, while values of $P<0.01$ were considered statistically highly significant, and $P<0.001$ were statistically very highly significant.

\section{RESULTS}

\section{Biochemical Analysis}

Lipid peroxidation products (thiobarbituric acid reactive substances, TBARS) concentration: Data regarding the effect of daidzein and vitamin $\mathrm{C}$ administration on blood thiobarbituric acid reactive substances (TBARS) concentration of $\gamma$-irradiated rats were shown in (Figure 1).

TBARS revealed a significantly increased concentration in blood of $\gamma$-irradiated rats $(205.457 \pm 2.494 \mathrm{mml} / \mathrm{L})$ as compared to normal control rats $(160.100 \pm 1.235 \mathrm{mml} / \mathrm{L})$. Treatments of $\gamma$-irradiated rats with any of the tested agents (daidzein or vitamin $\mathrm{C}$ or daidzein concomitant with vitamin C) exhibited significant $(P<0.05)$ decrease in TBARS concentration when compared with irradiated control group. One-way ANOVA analysis revealed that the general effect in between groups was very highly significant $(P<0.001)$ throughout the experiment.

Blood enzymatic antioxidant defense parameters (glutathione peroxidase, GPx, superoxide dismutase, SOD and catalase, CAT): Data representing the activities of antioxidant enzymes in blood of $\gamma$-irradiated rats are shown in (Figures 2,3 and 4). The antioxidant enzymes (GPx, SOD, and CAT) exhibited a significantly $(P<0.05)$ decreased activities in the blood of irradiated rats as compared to normal ones. Otherwise, the intake of the tested agents produced a marked alleviation of these alterations as compared to the irradiated group. GPx activity was significantly $(P<0.05)$ decreased in the daidzein-treated group when compared to normal rats. The CAT activity was significantly $(P<0.05)$ decreased in vitamin $\mathrm{C}$ treated group as compared to the normal control group. One-way ANOVA analysis revealed that the general effect between groups was very highly significant $(P<0.001)$ throughout the experiment.

Serum urea concentration: The recorded values of fasted irradiated rats (Figure 5) showed a significant $(P<0.05)$ increase of serum urea concentration $(46.933 \pm 0.817 \mathrm{mg} / \mathrm{dl})$ as compared with that of normal control $(21.200 \pm 1.070 \mathrm{mg} /$ dl). Treatments of irradiated rats with any of the tested agents significantly $(P<0.05)$ decreased serum urea concentrations. Administration of daidzein concomitants with vitamin $\mathrm{C}$ appeared to be the most potent one; the recorded value was $37.658 \pm 0.496 \mathrm{mg} / \mathrm{dl}$ as compared to the irradiated group (46.933 $\pm 0.817 \mathrm{mg} / \mathrm{dl})$. Regarding One-way ANOVA analysis, the general effect in between groups was very highly significant $(P<0.001)$ throughout the experiment.

Serum creatinine concentration: Results shown in (Figure 6) revealed a significant increase of creatinine concentration in serum of $\gamma$-irradiated rats $(2.873 \pm 0.071 \mathrm{mg} /$ dl) when compared with normal rats $(0.647 \pm 0.052 \mathrm{mg} /$ dl). Treatments of irradiated rats with any of the tested agents induced a significant decrease of serum creatinine concentration as compared with the corresponding irradiated 
rats. Administration of either daidzein or vitamin $\mathrm{C}$ to normal rats significantly elevates serum creatinine concentration as compared to the normal group. Concerning one-way ANOVA analysis, the general effect among groups was very highly significant $(P<0.001)$ throughout the experiment.

\section{Serum Uric Acid Concentration}

Uric acid exhibited significantly increased concentration $(8.677 \pm 0.179 \mathrm{mg} / \mathrm{dl})$ in the serum of $\gamma$-irradiated group as compared to the normal one $(3.767 \pm 0.082 \mathrm{mg} / \mathrm{dl})$ (Figure 7). After treatments, all $\gamma$-irradiated- treated groups revealed a significant decrease in uric acid concentration; the obtained values were $7.212 \pm 0.156,6.302 \pm 0.050$ and $6.033 \pm 0.084 \mathrm{mg} / \mathrm{dl}$ for daidzein, vitamin $\mathrm{C}$ and daidzein + vitamin $\mathrm{C}$, respectively.

One-way ANOVA analysis revealed that the general effect in between groups was very highly significant $(P<0.001)$ throughout the experiment.

\section{Histopathological Study}

In control untreated and control antioxidants treated rats, microscopic investigation of the kidney revealed normal histological architecture (Figures 8a and b). Renal parenchyma can be discriminated into an outer cortex and an inner medulla. The outer cortex contains the renal corpuscles which appear as large spherical structures and renal tubules (proximal and distal tubules). Each renal corpuscle is surrounded by a thin capsule (Bowman's capsule) composed of simple squamous epithelial cells; this capsule encloses the urinary space and the capillary tuft or (glomerulus). The proximal convoluted tubules have a larger diameter than the distal tubules and have brush borders and narrow lumens, the walls of the proximal convoluted tubules consist of few cuboidal cells of large and spherical nuclei. The distal tubules have no brush borders and their lumens are wider and more conspicuous than that of proximal convoluted tubules (Figure 8b).

The kidney sections obtained from irradiated rats revealed clear destructive alterations in the glomerular tufts and renal tubules (Figures 9a and b). Ruptured wall of Bowman's capsule and dilation in the lumen of renal tubules were observed (Figures 9a and b). Some glomeruli appeared swollen with diffused and fragmented tufts and others appeared damaged loosing, approximately, its cellularity (Figures 9a and b). Some glomeruli showed an obvious degree of shrinkage with rupture and loss of glomerular tufts. Signs of interstitial hemorrhage was also detected (Figure 9a). Cells of renal tubules (distal and proximal tubules) showed cytoplasmic vacuolation and pyknotic nuclei (Figure 9b).

The kidney sections obtained from male rats treated with daidzein revealed a marked improvement in the cortex when compared to those of the $\gamma$-irradiated group (Figs. 10a $\& b)$. Most renal tubules and renal corpuscles approximately regained their normal appearance (Figures 10a and b).
The kidney sections obtained from male rats treated with vitamin $\mathrm{C}$ showed less renal tubular modifications than that of $\gamma$-irradiated group. The renal tubules were less dilated (Figures 11a and b). Many renal corpuscle and renal tubules appeared nearly normal (Figures $11 \mathrm{a}$ and $\mathrm{b}$ ).

The kidney sections obtained from male rats treated with vitamin $\mathrm{C}$ and daidzein showed an obvious improvement compared to irradiated ones except for the detection of some histological changes (Figures 12a and b). The morphology of the kidney was almost similar to that of the normal (Figures 12a and b).

\section{Electron Microscopic Investigation}

The renal corpuscle of control untreated rats seems as dense round tufts of capillaries. Bowman's capsule consists of outer parietal layer and inner visceral layer. The capillaries are surrounded by podocytes. The endothelial cells lined the capillary loop (Figure 13a). The podocytes give many primary processes which give many secondary foot processes that rest on a thin basal lamina (Figure 13a). Each podocyte has abundant cytoplasm and large nucleus. The pedicels are separated by slit pores. The filtration barrier comprises capillary endothelial inner layer, thin glomerular basement membrane and podocyte layer (Figure 13a).

The proximal tubules consist of cuboidal cells with brush border of several microvilli and cytoplasm with many organelles (Figure 13b). The nucleus appeared spherical and located at the center. Areas of heterochromatin are detected at the nuclear membrane. Many mitochondria, with closely parallel cristae and highly dense matrix, fill the perinuclear and basal cytoplasm. The basal infoldings run upward among the mitochondria (Figure 13b).

Examined kidney sections obtained from irradiated rats revealed complete degeneration of foot processes and thickening of the glomerular capillary basement membrane (Figure 14a). The cells of proximal convoluted tubule showed cytoplasmic vacuolization and dissolution of some parts. Many cells showed loss of their brush borders and rupture of their cell membranes, with cytoplasm protruding into the lumen. The lumen of many tubules was occupied with cell debris (Figure 14b). The most damaged organelle appeared to be the mitochondria, which were electron lucent and showed swelling, with loss of cristae. Lysosomes and several mitochondria contained spaces or vacuoles were observed (Figure 14b).

After treatment with daidzein, the renal corpuscle suffered from changes like those observed in the $\gamma$-irradiated group although there was a slight improvement in some features (Figure 15a). The glomerular tuft showed a reappearance of glomerular foot processes and the capillary were observed contain RBCs (Figure 15a).

The cells of proximal tubules showed a reduced basal lamina thickening (Figure 15b). The nuclei recovered their normal appearance. Few electron-lucent mitochondria and 
cytoplasmic vacuolization were observed. The brush border appeared nearly normal with cytoplasm extruding into the lumen. Though, the cytoplasmic alterations were milder than those seen in the $\gamma$-irradiated group (Figure 15b).

The kidney of rats supplemented by vitamin $\mathrm{C}$ as radioprotector revealed mild improvement in the renal corpuscle and proximal tubules (Figures 16a and b). The glomerular tuft showed a reappearance of foot processes (Figure 16a). The proximal tubular cells showed better preservation in comparison to those of irradiated rats (Figure 16b). The nuclei appeared spherical in shape with normal distribution of chromatin (Figure 16b). The mitochondria were elongated and numerous with closely

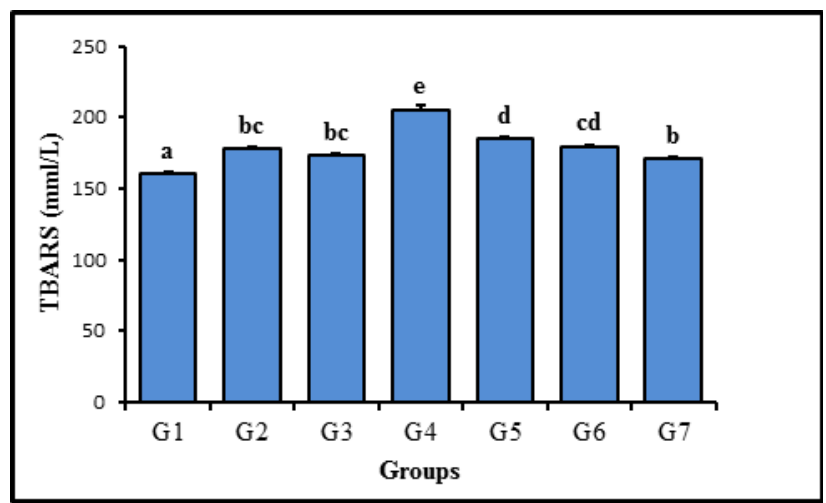

Fig. 1: Effect of daidzein and /or vitamin $\mathrm{C}$ administration to rats either/ neither gamma irradiated on the TBARS level in rats serum. Columns that do not share the same letter, are significantly different. significance level $<0.05$

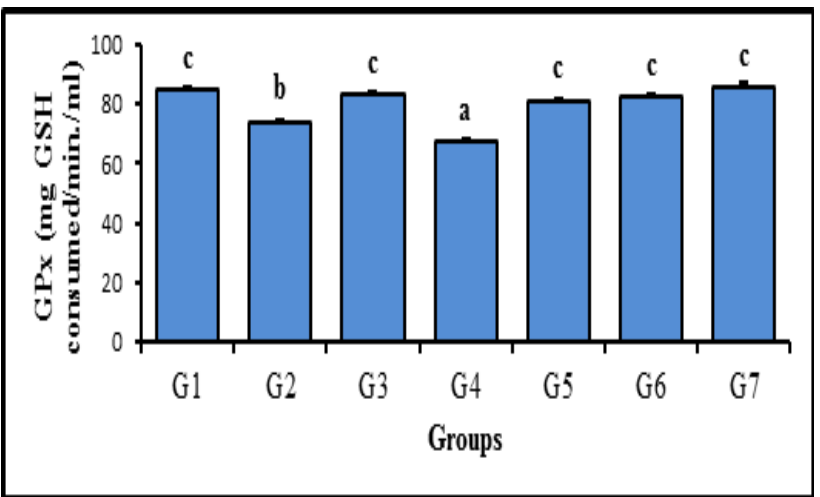

Fig. 2: Effect of daidzein and /or vitamin $\mathrm{C}$ administration to rats either/ neither gamma irradiated on the GPx activity in rats serum. Columns that do not share the same letter, are significantly different. significance level $<0.05$. parallel cristae (Figure 16b). In most sections, basal and apical membranes appeared normal.

Ultrathin sections of kidneys of rats supplemented by vitamin $\mathrm{C}$ and daidzein as radioprotectors established some light microscopic features of normal renal ultrastructure (Figure 17a). The glomeruli, capillary lumen, podocytes, and foot processes of podocytes appeared normal (Figure 17a).

The proximal tubular cells showed better appearance compared to those of the irradiated group. The nuclei looked spherical with normal chromatin distribution (Figure 17b). The basal infoldings extend deeply into the cytoplasm. Numerous elongated mitochondria with closely parallel cristae were observed. The basal and apical cell membranes appeared normal (Figure 17b).

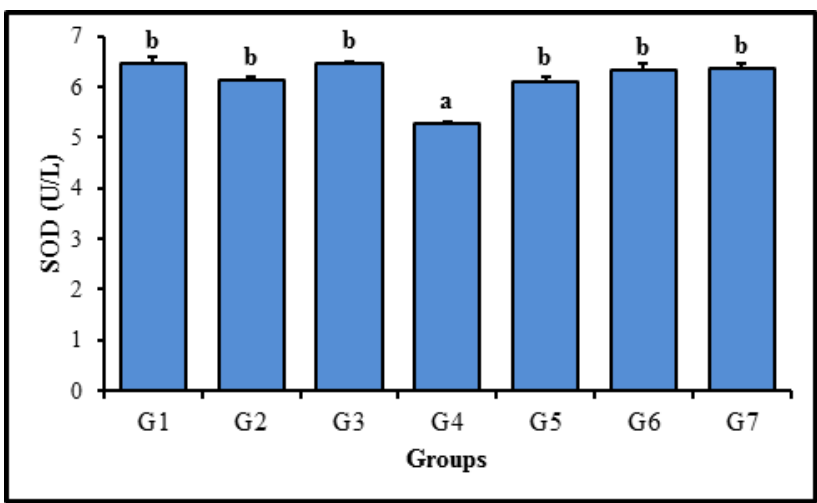

Fig. 3: Effect of daidzein and /or vitamin $\mathrm{C}$ administration to rats either neither gamma irradiated on the SOD activity in rats serum. Columns that do not share the same letter, are significantly different. significance level $<0.05$.

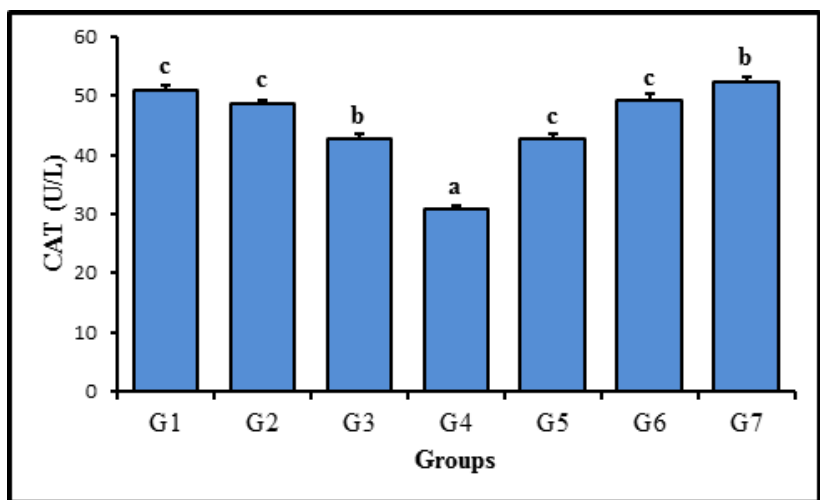

Fig. 4: Effect of daidzein and /or vitamin $\mathrm{C}$ administration to rats either/ neither gamma irradiated on the CAT activity in rats serum. Columns that do not share the same letter, are significantly different. significance level $<0.05$. 


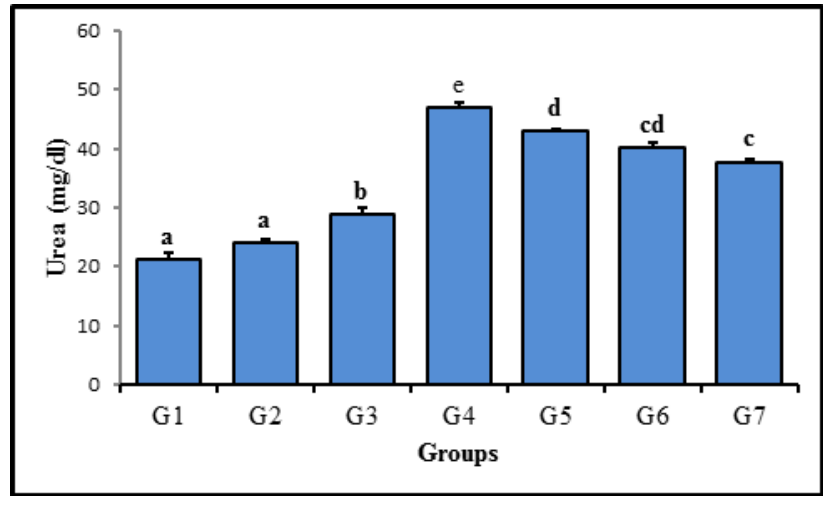

Fig. 5: Effect of daidzein and /or vitamin C administration to rats either/ neither gamma irradiated on the urea level in rats serum. Columns that do not share the same letter, are significantly different. significance level $<0.05$

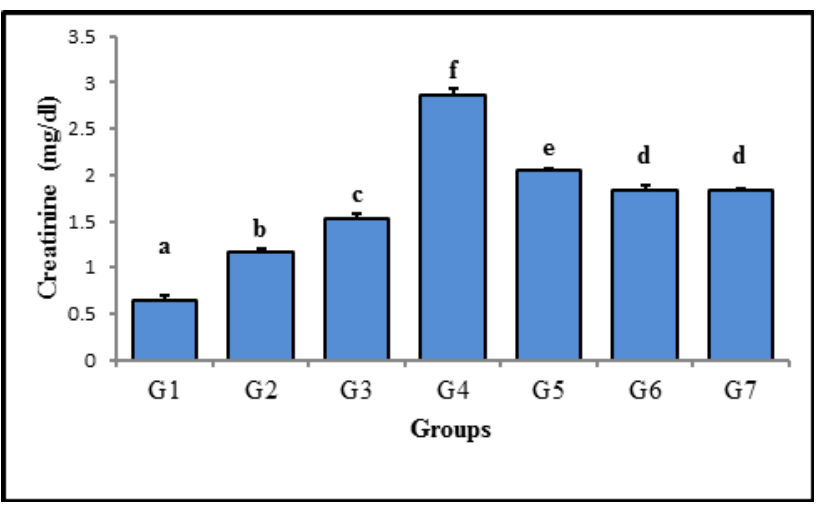

Fig. 6: Effect of daidzein and /or vitamin C administration to rats either/ neither gamma irradiated on the creatinine level in rats serum. Columns that do not share the same letter, are significantly different. significance level $<0.05$

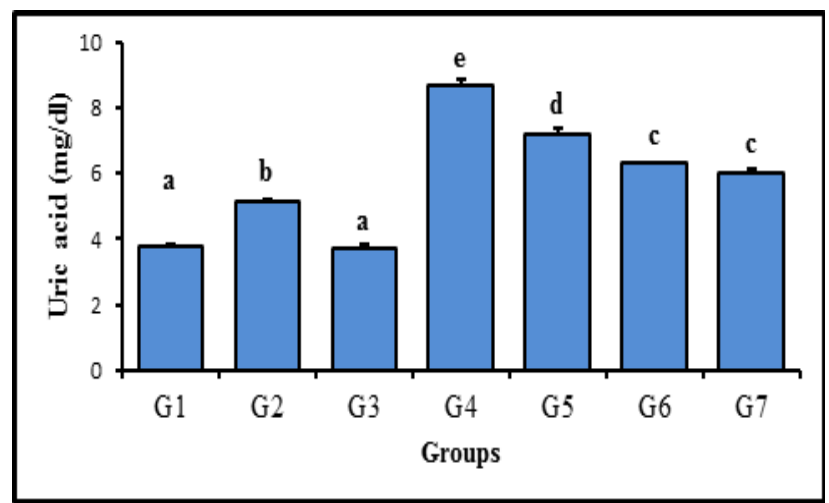

Fig. 7: Effect of daidzein and /or vitamin $\mathrm{C}$ administration to rats either/ neither gamma irradiated on the uric acid level in rats' serum. Columns that do not share the same letter, are significantly different. significance level $<0.05$.
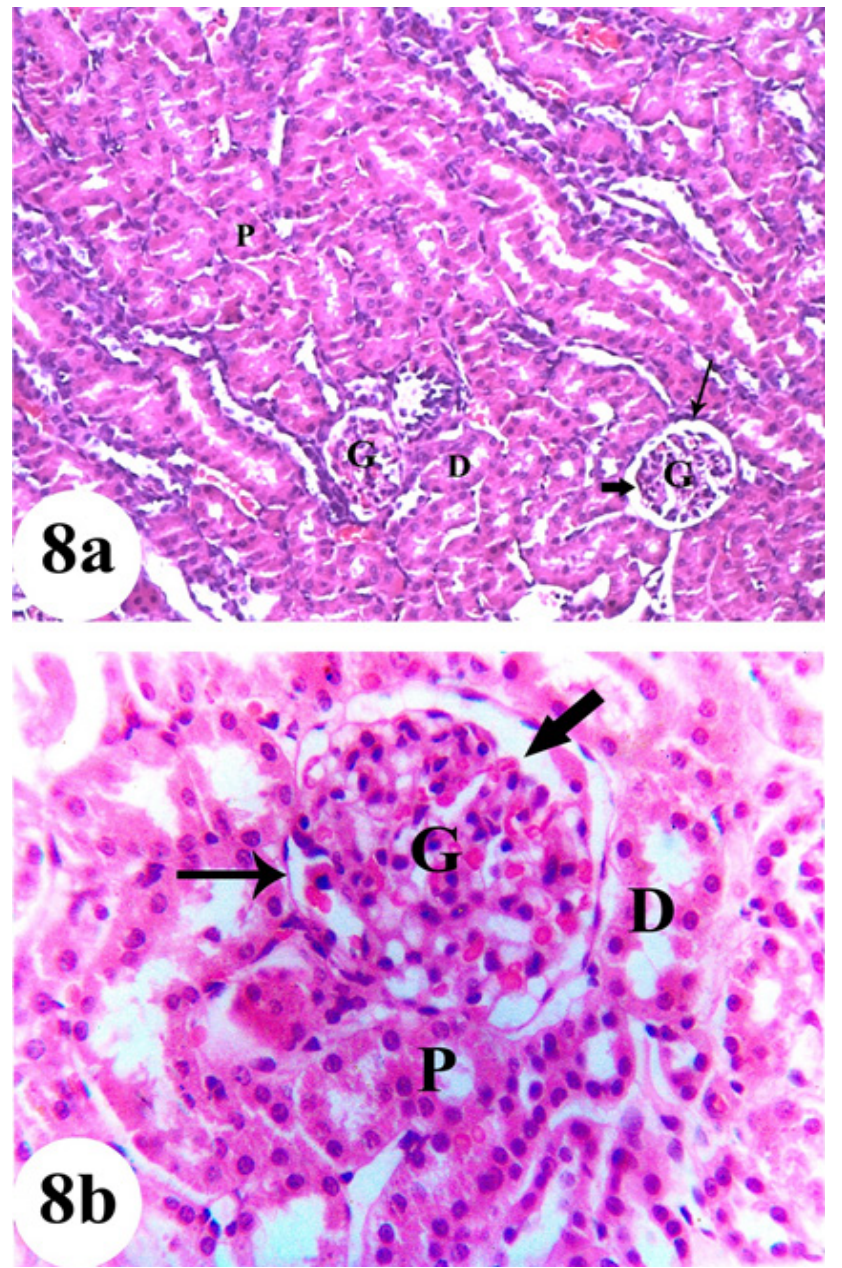

Figs. 8a \&b: Light micrographs of a cross-section in the cortex of the kidney of a normal control rat, illustrating the normal appearance of Bowman's capsule (thin arrow), urinary space (thick arrow) and glomerular tuft $(\mathrm{G})$. Note the proximal (P) and distal (D) convoluted tubules. (H\&E., a: X100 \&b: X400)

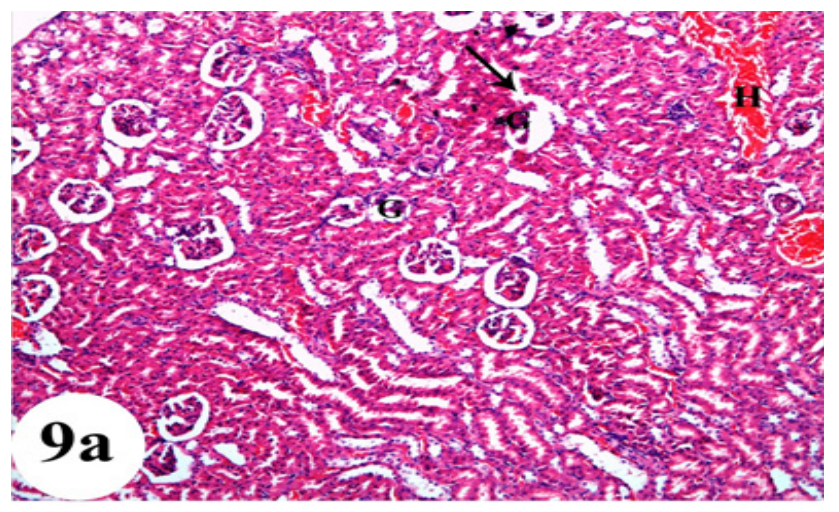

Fig. 9a: Light micrograph of a cross-section in the cortex of the kidney of irradiated rat, showing a raptured wall of Bowman's capsule (arrow), interstitial hemorrhage $(\mathrm{H})$ and obvious shrunken glomerular tuft $(\mathrm{G})$. (H\&E., X100) 


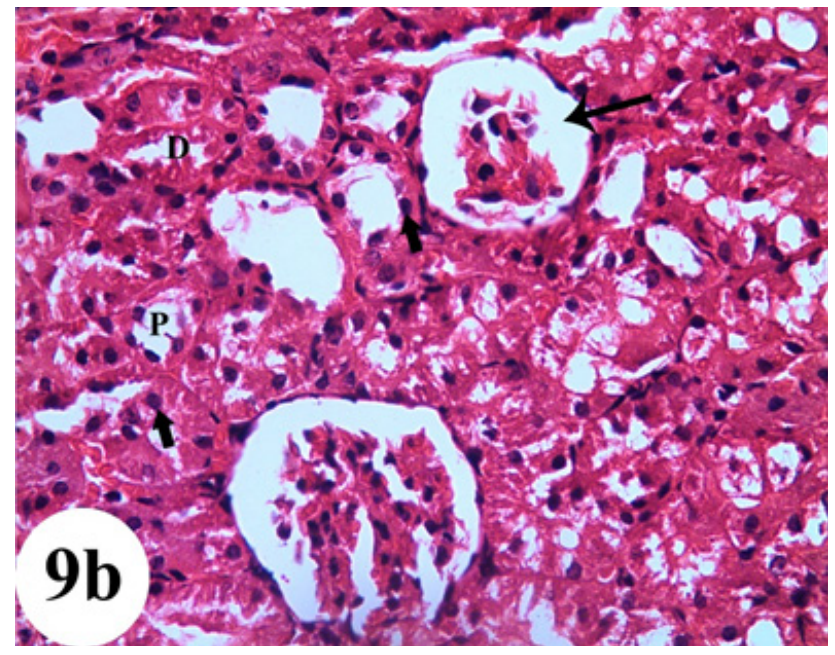

Fig. 9b: Light micrographs of a cross-section in the cortex of the kidney of irradiated rat, showing shrunken glomerulus, widened urinary space (thin arrow) and cellular damaged of both distal (D) and proximal (P) convoluted tubules. Note also many pyknotic nuclei (thick arrow). (H\&E., X400)
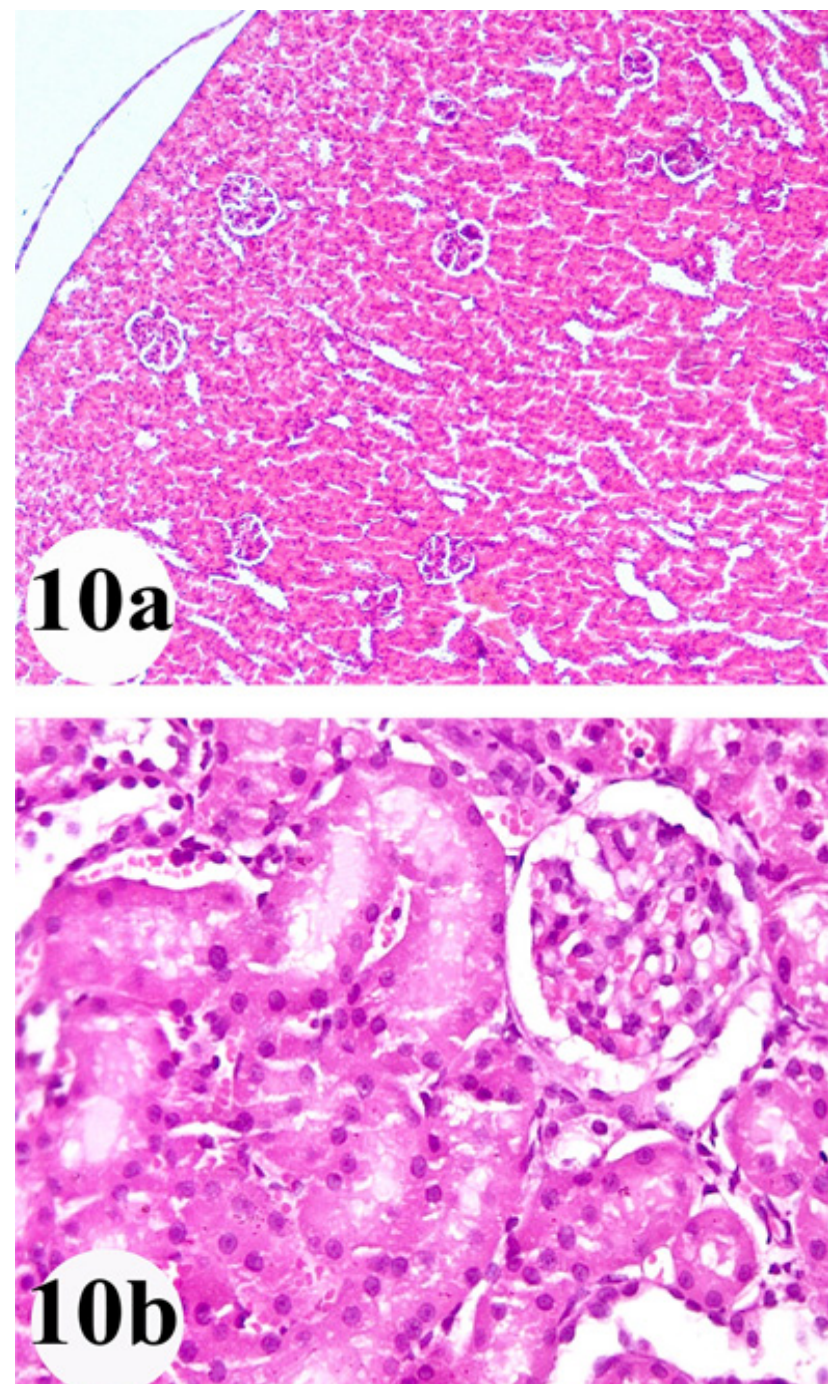

Figs. 10 a\& b: Light micrographs of a cross section in the cortex of the kidney of irradiated rat treated with daidzein showing approximate regain of the normal appearance of the tubules and renal corpuscle. (H\&E., a: X100 \&b: X400)

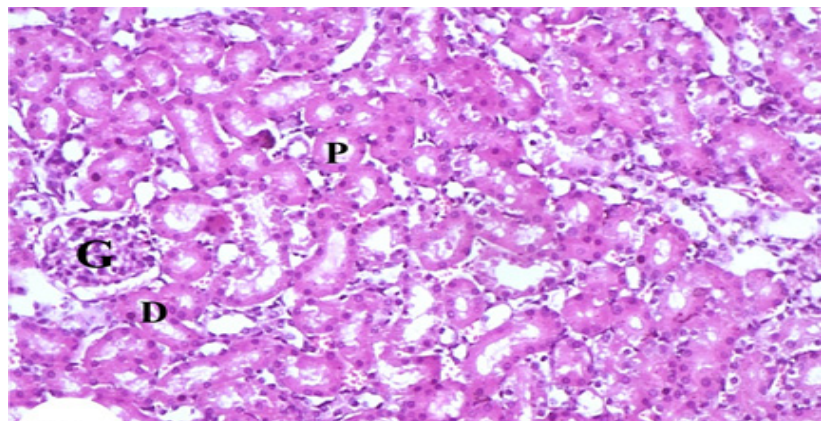

$11 \mathbf{a}$ a - 69 J

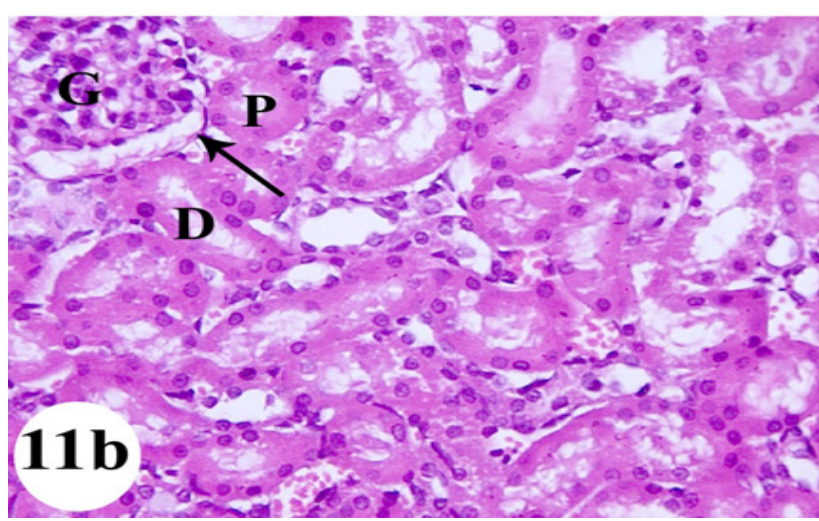

Figs. $11 \mathrm{a} \& \mathrm{~b}$ : Light micrographs of a cross-section in the cortex of the kidney of irradiated rat treated with vitamin $C$ showing nearly norma glomeruli (G), urinary space (arrow), distal (D) and proximal (P) tubules. (H\&E, a: X100 \&b: X400)
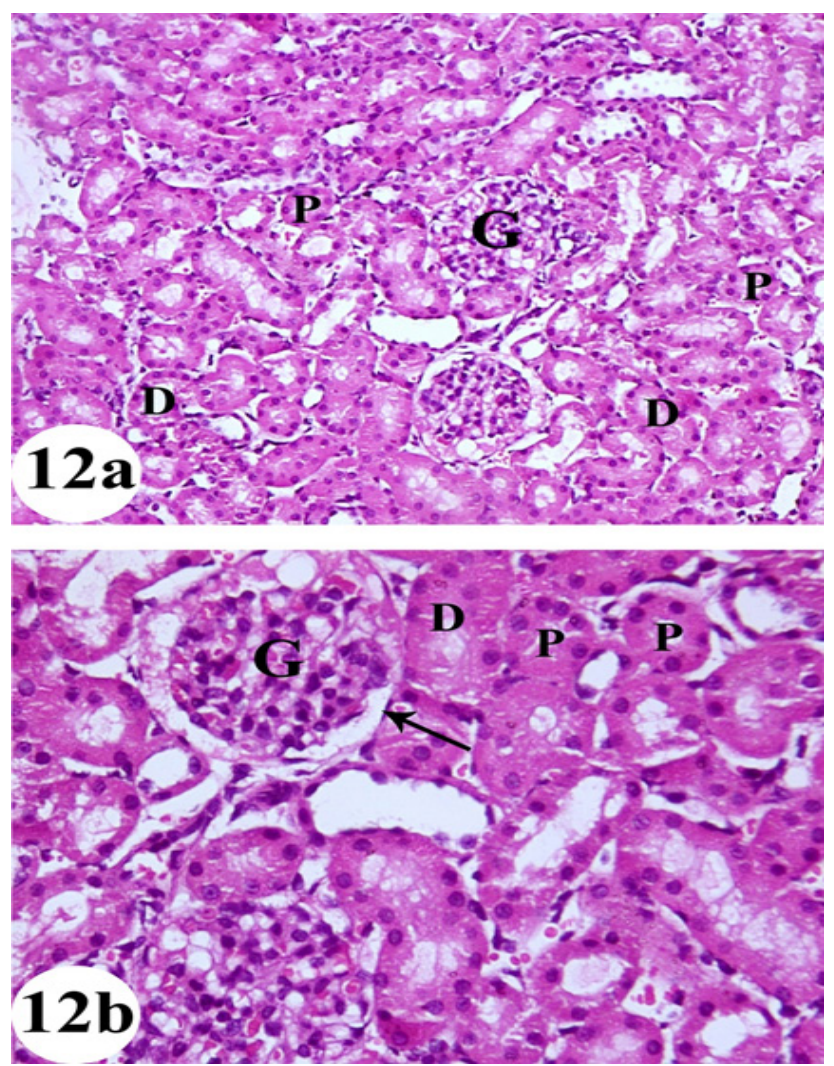

Figs. 12 a\& b: Light micrographs of a cross-section in the cortex of the kidney of irradiated rat treated with daidzein and vitamin $\mathrm{C}$, showing the glomerulus (G), Bowman's capsule (arrow), distal (D) and proximal (P) renal tubules regained their normal structures. (H\&E, a: X100\& b: X400) 


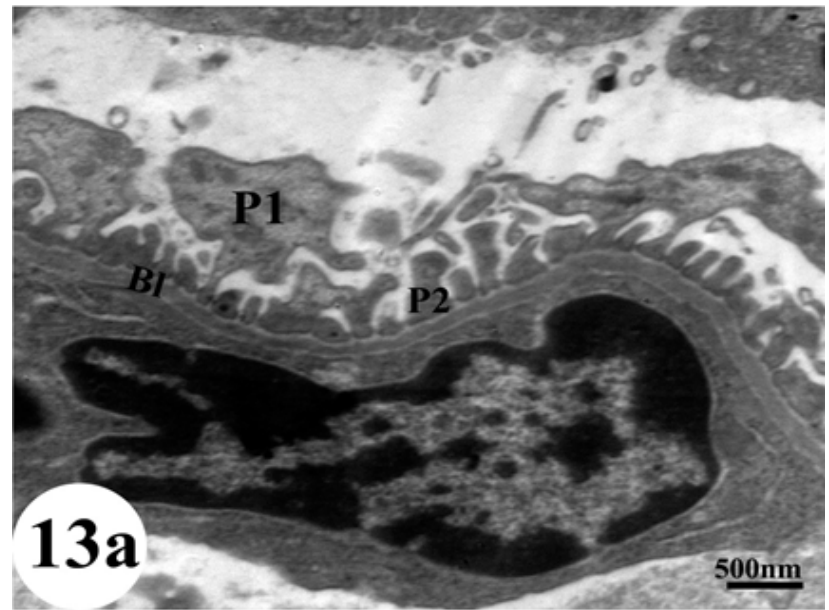

Fig. 13 a: Electron micrograph of a renal corpuscle of a control rat showing the podocyte that gives primary processes (PI) which in turn gives many secondary foot processes $(\mathrm{P} 2)$ or pedicles that rest on basal lamina (B1). TEM, $\times 4000$

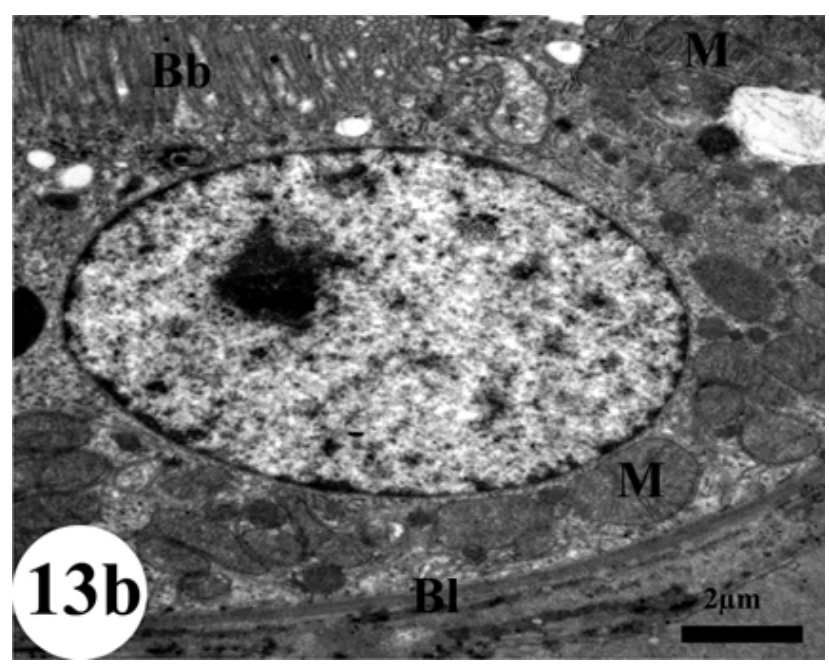

Fig. 13b: Electron micrograph of a part of a proximal convoluted tubule of control rat's kidney showing mitochondria (M) with normal cristae in between basal infoldings. Note proximal tubule with thin basal lamina (B1), regular nucleus and brush border $(\mathrm{Bb})$ with various microvilli. TEM, $\times 2500$

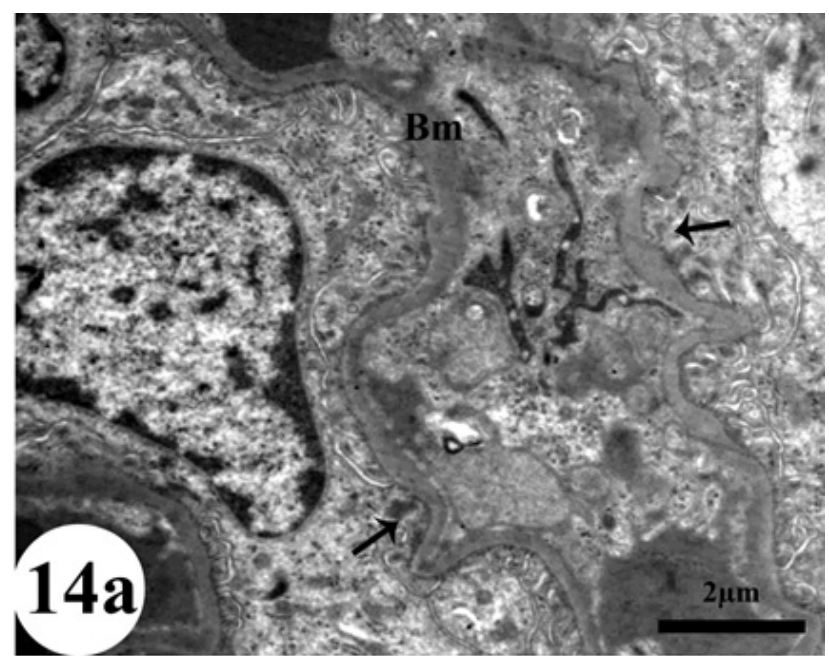

Fig. 14 a: Electron micrograph of a part of a glomerular tuft of irradiated rat's kidney showing complete degeneration of foot processes (arrows) of podocytes and thickening of the glomerular basement membrane $(\mathrm{Bm})$. TEM, $\times 3000$

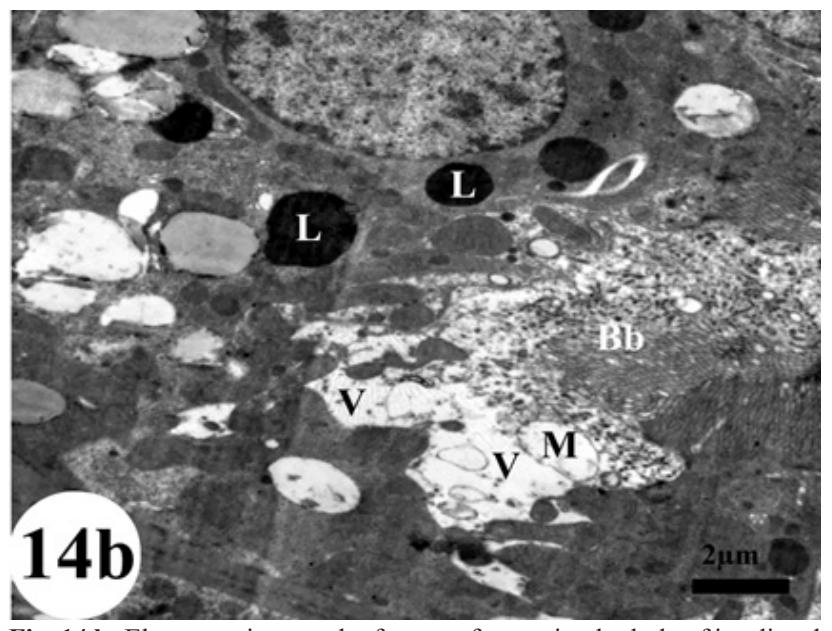

Fig. 14 b: Electron micrograph of a part of a proximal tubule of irradiated rat's kidney showing raptured brush border $(\mathrm{Bb})$, many mitochondria with raptured cristae (M), vacuolated cytoplasm (V) and lysosomes (L). TEM, $\times 2000$

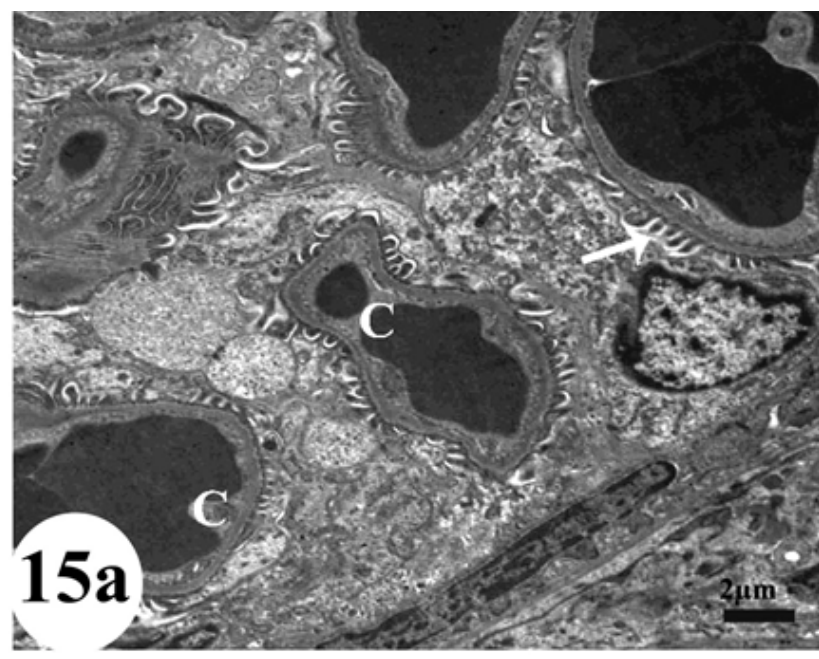

Fig. 15 a: Electron micrograph of a part of a glomerular tuft of irradiated rat's kidney treated with daidzein, showing capillary (C) were observed contain RBCs. Note the reappearance of foot processes (arrow). TEM, $\times 1500$

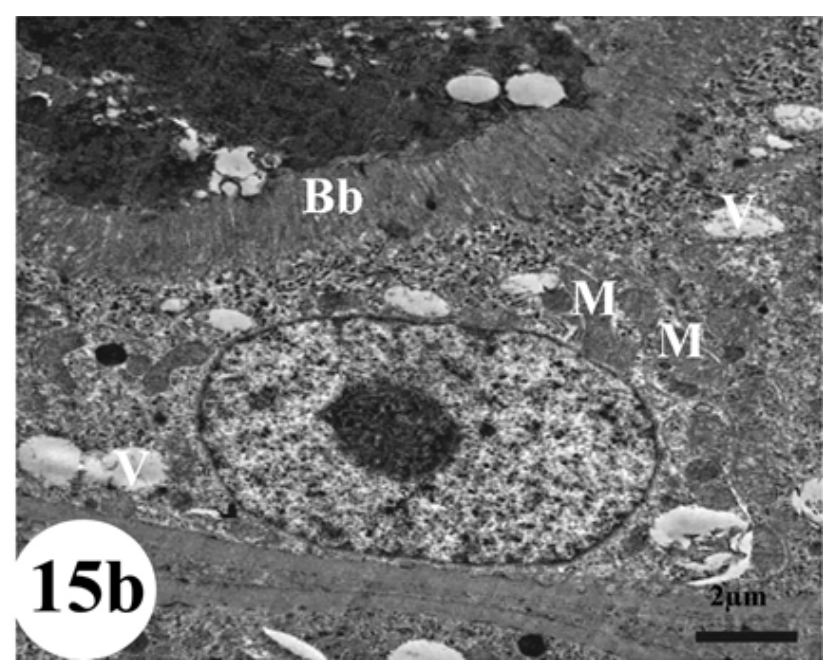

Fig. $15 \mathrm{~b}$ : Electron micrograph of a part of a proximal tubule of irradiated rat's kidney treated with daidzein, showing nearly normal mitochondria (M), brush border (Bb) and vacuolated cytoplasm (V). TEM, $\times 2000$ 


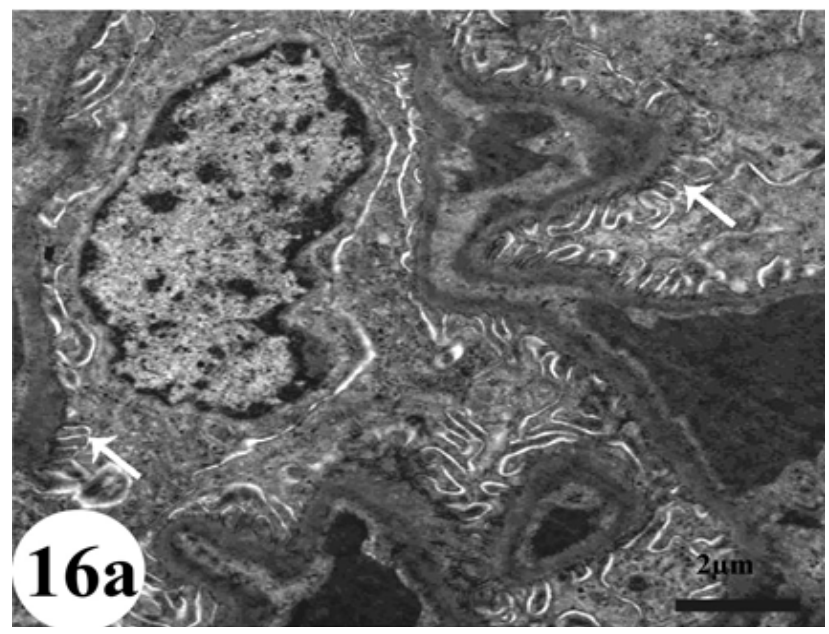

Fig. 16 a: Electron micrograph of a part of glomerular tuft of irradiated albino rat's kidney treated with vitamin $\mathrm{C}$, showing a reappearance of foot processes (arrows). TEM, $\times 2500$

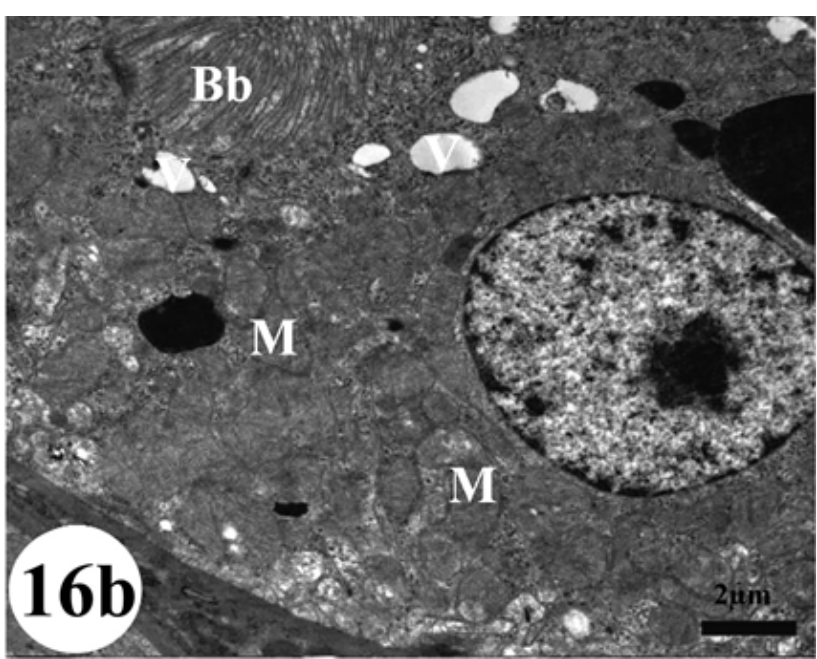

Fig. 16 b: Electron micrograph of a part of a proximal tubule of irradiated albino rat's kidney treated with vitamin $\mathrm{C}$, showing nearly normal mitochondria $(\mathrm{M})$, brush border $(\mathrm{Bb})$ and some vacuoles in the cytoplasm (V). TEM, $\times 2000$

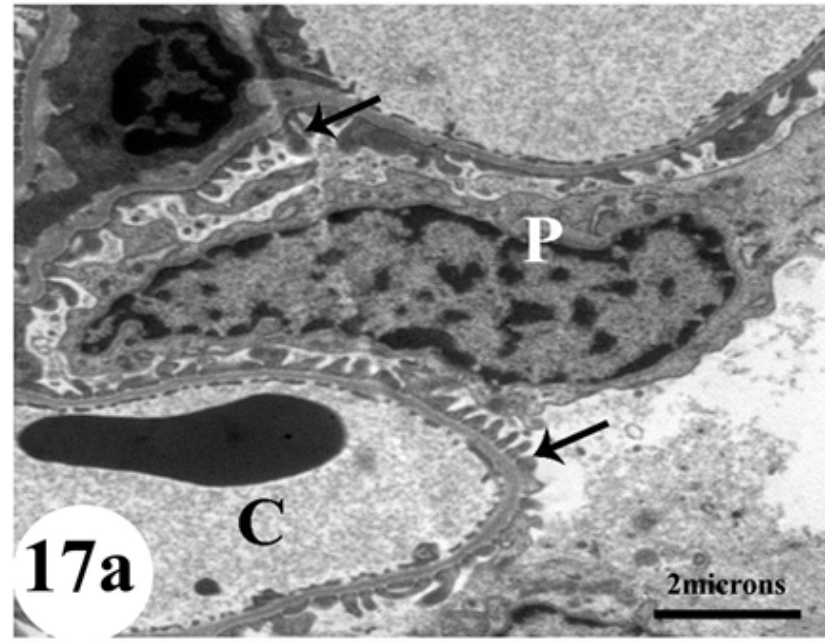

Fig. 17 a: Electron micrograph of a part of a glomerular tuft of irradiated albino rat's kidney treated with daidzein and vitamin $\mathrm{C}$, showing normal capillary lumen $(\mathrm{C})$, podocytes $(\mathrm{P})$ and foot processes (arrows). Note the reduction of the glomerular capillary basement membrane. TEM, $\times 2000$

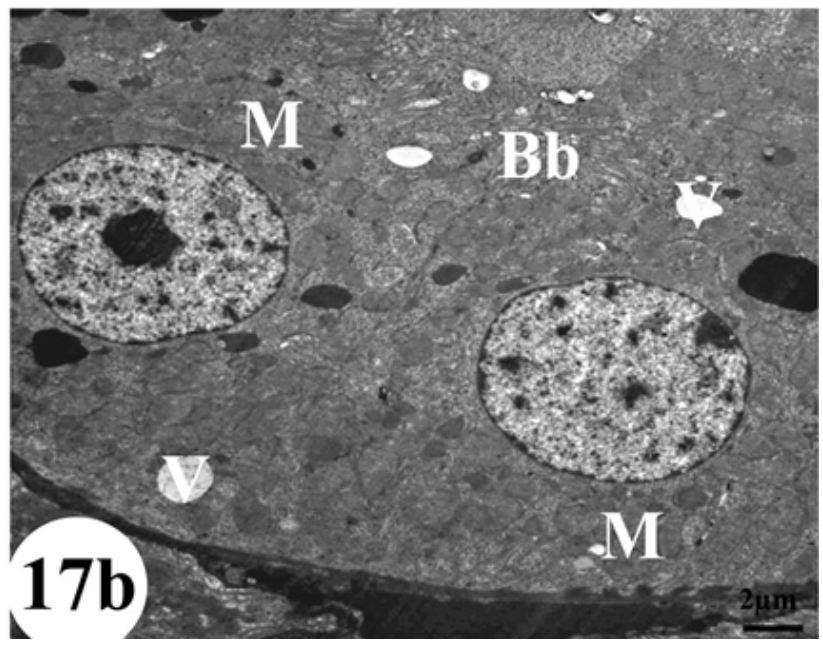

Fig. 17 b: Electron micrograph of a part of a proximal tubule of irradiated albino rat's kidney treated with daidzein and vitamin C, showing nearly normal brush border $(\mathrm{Bb})$, mitochondria $(\mathrm{M})$, and cytoplasmic vacuolation (V). TEM, $\times 1200$

\section{DISCUSSION}

The medical uses of radiation have been increased rapidly during the last decade due to the progress of new diagnostic and therapeutic methods using $\gamma$ rays in medicine ${ }^{[1]}$. It has been revealed that radiotherapy kills tumor cells and affects the health and survival of the surrounding normal cells ${ }^{[31]}$. So, the aim of this study is to assess the probable protective effect of vitamin $\mathrm{C}$ and daidzein, against kidney injury caused by $\gamma$-radiation in rats. This was achieved by assessing some biochemical parameters together with light and electron microscopic examinations of the kidney in male albino rats.

Results of the present study indicated that exposure of whole body at 8 Gy of $\gamma$-irradiation lead to biochemical illnesses, established by significant elevation of serum urea, creatinine, uric acid, and TBARS, while a significant decline in SOD, GPx, and CAT activity were recorded.

The elevated levels of TBARS suggest an elevated level of oxygen free radicals which could be due to their elevated production or decreased destruction. Some researchers have suggested an association between MDA and $\gamma$ rays-induced complications ${ }^{[32]}$. A possible explanation for the increased MDA concentration may be due to decreased formation of antioxidants in tissues of $\gamma$-irradiated animals as reported by Nada et al. ${ }^{[33]}$ which in view of increased activity of ROS permits a following increase in MDA production. The increase in TBARS detected in this study was parallel to the decrease in GPx concentration in the serum of $\gamma$-irradiated rats, where GSH, as a potent reducing agent can disrupt the radical chain production of lipid peroxidation. Leedle and Aust ${ }^{[34]}$ revealed that peroxidation of membrane phospholipids is linked to an insufficient GSH concentration. The plasma concentrations of different antioxidants decreased significantly during $\gamma$-irradiation ${ }^{[1]}$. The decreased levels of physiological antioxidants defense mechanism may lead to increased oxidative stress and free radicals-induced tissue damage. 
Excessive lipid peroxidation can raise $\mathrm{GSH}$ consumption $^{[35]}$. Elevation of MDA after radiation exposure could be related to improved consumption of the antioxidant system in an effort to detoxify radiation produced free radicals ${ }^{[36]}$ which probably accounts for the decline of SOD and CAT actions.

The reduction in GSH and increase in MDA are in agreement with those reported by Abou-Zeid et al. ${ }^{[37]}$, who found a significant decrease in the antioxidant system and improvement of lipid peroxides after whole body $\gamma-$ irradiation. At normal state, the natural defense system, comprising GSH and the antioxidant enzymes, protects against oxidative injury.

In the current study, a significant increase in urea, uric acid and creatinine were observed in the $\gamma$-irradiated group. Similar results have been recorded by Gazar et al.$^{[38]}$. Serum urea and creatinine are the main markers of nephrotoxicity and hepatorenal syndrome. Radiation induces an increase in the levels of glutamate dehydrogenase enzyme, which might increase carbamoyl phosphate synthetase activity and finally led to an increase in urea concentration ${ }^{[39]}$. Serum urea concentration is closely parallel to the glomerular function ${ }^{[40]}$. The increase in serum urea content of irradiated rats, in the present study, may be due to kidney dysfunction as confirmed by histological results. The increase in uric acid concentration might be due to kidney urate elimination and inefficiency of glomerular filtration in nephrons. Further, it may lead to hyperuricemia due to more tubular reabsorption, mediated by urate exchanger and voltage-sensitive urate channel in proximal convoluted tubules ${ }^{[41]}$.

The present results of serum markers and antioxidant parameters were associated with the histopathological examination. In the present study, light microscopic examination of the kidney of rats exposed to $\gamma$-rays showed severe changes of kidney parenchyma compared to the control. These lesions were represented mainly by shrinkage in glomeruli, interstitial hemorrhage, degenerated renal convoluted tubules and increase in the inflammatory cells as has been reported by Eissa and Mostafa ${ }^{[42]}$. Previous histological studies on the effects of $\gamma$-rays on the kidney structures have been reported in experimental animals. Some authors reported glomerular damage under the effect of irradiation ${ }^{[43]}$. In the current study damage in glomerular tuft was observed with widening in the urinary space of Bowman's capsule. This result was in agreement with that of Abu-Nour et al. ${ }^{[44]}$ who reported that glomeruli appeared to be very radiosensitive because all glomeruli of irradiated kidneys were distorted when compared to controls. The atrophy in some glomerular tufts in the present study may be due to whole-body $\gamma$-irradiation in rats. The interstitial congestion observed in the glomerular tufts may be related to the dilation in the peripheral blood vessels which induced by exposure to $\gamma$-radiation as suggested by Katzung ${ }^{[45]}$. Moreover, there was a marked degeneration in the cells of renal tubules. Robbins et al. ${ }^{[46]}$ reported that the renal irradiation resulted in a decline in glomerular filtration rate (GFR). Exposure to radiation can also cause complete glomerular capillary obstruction due to thrombus formation. Data from experimental studies on mice, pigs, and primates as well as from clinical studies suggested that glomerular injury develops before tubular damage ${ }^{[46]}$ and that glomerular damage is associated with renal failure ${ }^{[47]}$. The destructed cells lining the proximal convoluted tubules was similar to that observed by Abu-Nour ${ }^{[48]}$. They reported that the tubular cells are one of the most important target cells for radiation injury and the endothelial cell injury represents the main site of radiation injury in the kidney.

The renal histopathological results reported in the present study, with $\gamma$-irradiated rats may be explained according to the ultrastructural observations. According to these observations, kidney showed a fusion of foot processes and thickening of the glomerular capillary basement membrane. The destruction of some proximal tubules, the formation of some necrotic tubular epithelial debris and loss of the normal border of the proximal tubular cells may result in tubular obstruction, producing a raised intratubular pressure which could lead to the reduction and impairment of the glomerular filtration rate. The formation of lipid peroxidation finally would change the composition of the glomerular basement membrane ${ }^{[49]}$. Moreover, deficiency in the ultrafiltration may be related to the thickening of the basement membrane ${ }^{[50]}$. This impairment leads to increased concentration of albumin in the glomerular filtrate associated with an increase in its catabolism by the renal tubules that leads to severe dilatation or swelling ${ }^{[51]}$. Vacuolated mitochondria and scattered lysosomes were also observed in the proximal tubules of $\gamma$-irradiated rats of the present study. These findings were confirmed by the previous authors who reported degenerative and necrotizing changes in the glomeruli and proximal tubules of irradiated mice ${ }^{[52]}$. Earlier studies have been reported that $\gamma$-radiation-induced nephrotoxicity is associated with oxidative stress and the lipid peroxidation is one of the mechanisms leading to kidney injury ${ }^{[53]}$. Cellular damage occurs due to disturbance of the dynamic equilibrium between prooxidant and free radicals scavenge by antioxidants ${ }^{[54]}$.

After administration of daidzein and vitamin $\mathrm{C}$, the morphology of the kidney was almost similar to that of normal. Antioxidants can act as free radical scavengers, and thus decrease some DNA damage induced by ionizing radiation (IR $)^{[55]}$. Theoretically, this action would permit cellular defenses to maintain pace with the free radicals formed by exposure to radiation. Radioprotective agents may suppress free radical generation, eliminate free radicals, stimulate natural radioprotector formation, improve DNA repair, decrease the post-radiation inflammatory reaction, or delay cellular division giving more time for cells to repair or go through apoptosis ${ }^{[56]}$.

So, it was reported that the synergistic effects of different antioxidants are responsible for their potent antioxidant and preventive effects of various diseases ${ }^{[57]}$. Isoflavones may provide protective effects in combination with dietary antioxidant nutrients, particularly with ascorbic acid and $\alpha$-tocopherol. Many free radical scavengers are useful in 
defense against nephrotoxicity induced by $\gamma$ rays $^{[58]}$. In agreement with the current study, Chen et al..$^{[59]}$ suggested that vitamin $\mathrm{C}$ reduces cisplatin-induced nephrotoxicity via reducing the formation of ROS.

One of the possible mechanisms that were recorded, for the defensive effect of daidzein, is the effect of soy protein on Insulin-like growth factor (IGF-1). IGF-1 is the main manager of renal remodeling and the animal studies revealed that soy protein-caused a reduction in circulating and renal IGF-1 ${ }^{[60]}$. The effect of soy protein on lipid and blood glucose levels is another mechanism for reducing kidney damage. Another mechanism is the antioxidant properties of daidzein, which can prevent the production of free radicals ${ }^{[6]]}$.

The present findings showed that supplementation of vitamin $\mathrm{C}$ and daidzein simultaneously as radioprotector minimized the effects of $\gamma$-radiation, where less or no histopathological or ultrastructural changes were observed. This reflects the protective effect of both antioxidants to scavenge the free radicals and supports the biochemical findings. The present results are in accordance with that of Wang et al. ${ }^{[57]}$ who reported that daidzein can protect lowdensity lipoprotein (LDL) from oxidative alteration, and its combination with vitamin $\mathrm{C}$ was better to the effect of it alone. Antioxidants functioning synergistically may work better than antioxidants working separately.

\section{CONCLUSION}

These results suggest that daidzein and /or vitamin $\mathrm{C}$ have a radioprotective property and could reduce the cytotoxic effect of radiation in rat kidney. The possible protective mechanism by daidzein and vitamin $\mathrm{C}$ might be radical scavenging. The protective effect of daidzein and/ or vitamin $\mathrm{C}$ against $\gamma$ rays-induced oxidative stress, in the present study, could be either directly by scavenging ROS and prevention of lipid peroxidation and/or indirectly through the improvement of the antioxidant activities of GPx, SOD, and CAT. The radioprotection index for the combination of daidzein and vitamin $\mathrm{C}$ was found to be more than daidzein or vitamin $\mathrm{C}$ separately. Therefore, daidzein and vitamin $\mathrm{C}$ could be used in combination to prevent and treat renal damage, induced by $\gamma$ rays. So, a diet rich in vitamin $\mathrm{C}$ and daidzein could inhibit $\gamma$-radiation-induced kidney damage and could also be valuable as a supportive care for people who exposed to $\gamma$ rays.

\section{FUNDING SOURCE}

This study was not funded by any source

\section{CONFLICT OF INTEREST}

There are no conflicts of interest.

\section{REFERENCES}

1. Shedid SM, Abdel-Magied N, Saada HN. Role of betaine in liver injury induced by the exposure to ionizing radiation. Environ Toxicol 2019; 34(2): 123-130.
2. El-Bahr SM. Biochemistry of free radicals and oxidative stress. Sci. Int. 2013; 1: 111-117.

3. Azzam EI, Jay-Gerin JP, Pain D. Ionizing radiation induced metabolic oxidative stress and prolonged cell injury. Cancer Lett 2012; 327: 48-60.

4. Filip C, Elena A, Nina Z, Irina J, Mihaela S, Luminita J, Nastasia G., Costel, MO. Hyperhomocysteinemia's effect on antioxidant capacity in rats. Cent Eur J Med 2010; 5(5): 620-626.

5. Boyacioglu M, Turgut H, Akgullu C, Eryilmaz U, Kum C, Onbasili, OA. The effect of L-carnitine on oxidative stress responses of experimental contrastinduced nephropathy in rats. J Vet Med Sci 2014; 76(1): $1-8$.

6. Weiss JF, Landauer MR. Protection against ionizing radiation by antioxidant nutrients and phytochemicals. Toxicol 2003; 189: 1-20.

7. Szeto YT, To TL, Pak SC and Kallec WA. study of DNA protective effect of orange juice supplementation. Appl Physiol Nutr Meta 2013; 38(5): 533-536.

8. Suhail N, Bilal N, Khan HY, Hasan S, Sharma S, Khan F, Mansoor T, Banu N. Effect of vitamins C and $\mathrm{E}$ on antioxidant status of breast cancer patients undergoing chemotherapy. J Clin Pharm Ther 2012; 37(1): 22-26.

9. Jagetia GC. Ascorbic acid treatment reduces the radiation induced delay in the skin excision wound of Swiss albino mice. Indian J Rad Res 2004; 1:7.

10. Mallikarjun Rao KV, Jagetia GC. Ascorbic acid treatment enhances the wound healing in mice exposed to radiation. Indian J Rad Res 2004; 1:24.

11. Russo AA, Acquavivia R, Campisi A, Sorrent V, Digiacomo C, Virgata G, Barecellona ML, Venella A. Bioflavonoids as antiradicals antioxidants and DNA cleavage protectors. Cell Biol Toxicol 2000; 16 (2):91-98.

12. Wiseman HO, Reilly JD, Adlercreutz H, Mallet AI, Bowey EA, Rowland IR, Sanders TA. Isoflavone phytoestrogens consumed in soy decrease $F(2)$ isoprostane concentrations and increase resistance of low density lipoprotein to oxidations in humans. Am J Clin Nutr 2000; 72: 395-400.

13. Banz W, Hauck S, Gename B, Winters T, Bartke A. Soy isoflavones modify liver free radical scavenger systems and liver parameters in Sprague-Dawley rats. J Med Food 2004; 7: 477-81.

14. Kang JL, Lee HW, Lee H.S. Genistein prevents nuclear factor kappa B activation and acute lung injury induced by lipopolysaccharide. Am J Respir Crit Care Med 2001; 164: 2206-2212. 
15. Sharma S, Sultana S. Modulatory effect of soy isoflavones on biochemical alterations mediated by TPA in mouse skin model. Food Chem Toxicol 2004; 42:1669-1675.

16. Choi EJ, Lee HB, Lee K and Chee KM. Long term combined administration of quercetin and daidzein inhibits quercetin induced suppression of glutathione antioxidant defenses. Food Chem Toxicol 2005; 43: 793-798.

17. Al-Yousuf HH. Chemopreventive effect of Daidzein on renal toxicity by targeting oxidative stress and inflammation. Int J Advanced Res 2015; 3(2): 506-521.

18. El Ashry MA, Salem FA, Yousri RM, Azab KS, AbdElRahman NA. Effect of daidzein to control hazard of radiation exposure and aflatoxin contamination. J environ Sci 2007; 15(1):167-188.

19. Abu Simmo E, El Dighidy E, Ashry O, Azzoz E. Influence of vitamins $\mathrm{C}$ and $\mathrm{E}$ on cigarette smoke inhalation injury in radiation exposed Guinea pigs. Egypt. J. Rad sci Applic 2010;23 (2): 217-231.

20. Henery RJ. Clinical chemistry. Principle and Technics $2^{\text {nd }}$ Edition. Harper Andraw; 1974: 525.

21. Weinstein MJ. Micobiology Research Division, Schering corporation. $19^{\mathrm{t}} \mathrm{h}$ ed., Bloom field. New Jersy, Newyork; 1973.

22. Patton CJ Crouch SR. Spectro-photometric and fine investigation of the bercheior reaction for the determine of Ammonia. Anal Chem 1977; 49(3): 464-469.

23. Yoshioka T, Kawada K, Shimada T, Mori M. Lipid peroxidation in maternal and cord blood protective mechanism against activated-oxygen toxicity in the blood. Am J Obstet Gynecol 1979; 135(3): 372-376.

24. Marklund S, Marklund G. Involvement of superoxide anion radical in autooxidation of pyrogallol and convenient assay for superoxide dismutase. Eur J Biochem 1974; 47: 469-474.

25. Bergmayer HV, Bergmayer J, Grab IM. In Methods of enzymatic analysis, 3rd.USA and Canda, VSH Publishers. 1987; p. 273.

26. Gross R, Racci Rudolph N, Schroeder E, and Kochen J. Hydrogen toxicity and detoxification in the erythrocytes and new born enfants. Blood 1967; 29 (4): 481.

27. Bancroft JD, Gamble M. Theory and Practice of Histological Techniques. $5^{\mathrm{t}} \mathrm{h}$ ed., Churchill Livingstone, London, 2002.pp.109-136.

28. Mercer EN, Birbeck MS. Electron Microscopy. A Handbook for Biologists. 2nd Ed. Blackwell Scientific Publications. Oxford; 1966.
29. Bozzola JJ, Russell LD. Electron Microscopy Principles and Techniques for Biologists. Jones and Bartlett Publishers, Sudbury; 1999.

30. IBM Corp. Released. IBM SPSS Statistics for Windows, Version 20.0. Armonk, N.Y.: IBM Corp; 2011.

31. Konopacka M, Rogolinski J. Thiamine prevents $\mathrm{X}$-ray induction of genetic changes in human lymphocytes in vitro. Acta Biochem. Pol., 2004.51: 839-843.

32. Sayed DF, Nada AS, Abd El Hameed MM, Ibrahim MT. Modulatory effects of Chrysophyllum cainito L. extract on gamma radiation induced oxidative stress in rats. Biomed Pharmacother 2019; 111: 613-623.

33. Nada AS, Hawasa AM, Abd Elmageedbc, ZY, Amin NE. Protective value of Aloe vera extract against $\gamma$-irradiation-induced some biochemical disorders in rats. Journal of Radiation Research and Applied Sciences 2013; 6: 31-37.

34. Leedle RA, Aust SD. The effect of glutathione on the vitamin $\mathrm{E}$ requirement for inhibition of liver microsomal lipid peroxidation. Lipids 1990; 25: 241-245.

35. Mansour H.H. Protective effect of ginseng against gamma-irradiation-induced oxidative stress and endothelial dysfunction in rats. EXCLI J 2013, 12: 766-777.

36. Krishna A, Kumar A. Evaluation of radioprotective effect of Rajira (Amaranthus paniculatus) extract in Swiss albino mice. J Rad Res 2005; 46: 233-239.

37. Abou-Zeid S, EL-bialy, BE, EL-borai NE, AbuBakr HO, Elhadary AM. Radioprotective effect of Date syrup on radiation- induced damage in Rats. Scientific Reports 2018; 8:7423.

38. Gazar AA Fahmy HA and Mohamed OS. Possible effect of wheat germ oil or beta-carotene to enhance kidney recovery processes in irradiated rats. Int J Res Pharm Sci 2016; 7 (4): 266-273.

39. Ramadan LA, Shouman SA, Sayed-Ahmed MM and El-Habit OH. Modulation of radiation-induced organs toxicity by cremophor-el in experimental animals. Pharmacol Res 2001; 43(2):185- 191.

40. Provoost AP, Molennar JC Changes in the glomerular filtration rate after unilateral nephrectomy in rats. Pflugers Arch 1980, 385: 161-165.

41. So A, Thorens B Uric acid transport and disease. J Clin. Invest. 2010, 120 (6):1791-1799.

42. Eissa OS, Mostafa A. Histological and histochemical study on the protective effect of WR-2721 against Cisplatin-induced nephrotoxicity in gamma irradiated female albino rats. Egypt J Rad Sci Applic 2009; 22 (1): 49-68. 
43. Mansoub MH, Sarvestani AH. Effects of gamma irradiation on histomorphology of different organs in rats. Annals Biol Res 2011; 2 (6):580-585.

44. Abu-Nour SM, Rady MI and Khalil IM. Protective effect of $\beta$-carotene on gamma radiation induced renal histological and ultrastructural changes in male albino rats. Al-Azhar Bull. Sci. 2008; 19(1):27-44.

45. Katzung BG. Basic and clinical pharmacology. $3^{\text {rd }}$ ed. Copyright by Appleton and Lange, printed in USA. 1987; pp. 336-349.

46. Robbins ME, Stephens LC, Thames HD, Gray KN, Peters LJ, Ang KK. Radiation response to the monkey kidney following contra lateral nephrectomy. Int. J. Rad. Oncol. Biol. Phys. 1995; 30: 347-354.

47. Robbins ME, Bonsib SM. Radiation and nephropathy: a review. Scanning Microsc. 1995; 9 (2): 535-560.

48. Abu-Nour SM. Radio-protective effect of garlic-oil on the kidney of male albino mice. (Histological and Histochemical studies). J. Egypt. Ger. Soc. Zool. 2002, 39(c): 391-410.

49. Haas M, Kerjaschki D, Mayer G. Lipid-lowering therapy in membranous nephropathy. Kidney International 1999; 56, Suppl. 71: S-110-S-112.

50. Cormack DH Ham's Histology. Essential Histology. JB Lippincott Company. London. New York. 1993.

51. More I, Briggs, J (1992): The kidney and urinary tract. In: Muir's Textbook of Pathology. 13 $3^{\text {th }}$ Ed. Edited by MacSween, R. and Whaley, K. Copublished in the United States of America by Oxford University Press. 891-945.

52. Tunez L, Munoz MC, Feijoo-Lopez AL, Valdvira E, Bujalance-Arenas L, Montilla P. Effect of melat-onin on hyperlipidemic nephropathy under constant light exposure. J Physiol Biochem 2002; 58(2): 109-114.
53. Mansour H., Abd El Azeem MG, Ismael NE (2014 b): Protective Effect of Moringa oleiferaon $\gamma$-RadiationInduced Hepatotoxicity and Nephrotoxicity in Rats. AJPCT, 2(4):495-508.

54. Rasoul E, Babak H, Hamze $M$ and Hadi S. Vitamin E ameliorates cyclophosphamide-induced nephrotoxicity. Life Sci J 2013; 10:308-3013.

55. Zhou R, Si J, Zhang H, Wang Z, Li J. The effects of $X$-ray radiation on the eye development of zebra fish. Hum Exp Toxicol 2014; 33(10):1040-1050.

56. Pei H, Chen W, Hu W, Zhu M, Liu T. GANRA-5 protects both cultured cells and mice from various radiation types by functioning as a free radical scavenger. Free Radic Res 2014;48(6):670-678.

57. Wang H, Martin MW, Yin S. The Synergistic Effect of Daidzein and $\alpha$-Tocopherol or Ascorbic Acid on Microsome and LDL Oxidation. Czech J Food Sci 2010, 28 (5): 385-391.

58. Elkady AA and Ibrahim IM. Protective effects of erdosteine against nephrotoxicity caused by gamma radiation in male albino rats. Hum Exp Toxicol 2016, 35(1):21-8

59. Chen MF, Yang CM, Su CM, Hu ML Vitamin C protects against cisplatin-induced nephrotoxicity and damage without reducing its effectiveness in C57BL/6 mice xenografted with Lewis lung carcinoma. Nutr Cancer 2014a, 66 (7):1085-1091.

60. Ogborn MR, Nitschmann E, Bankovic-Calic N, Weiler HA, Aukema HM Dietary soy protein benefit in experimental kidney disease is preserved after isoflavone depletion of diet. Exp Biol Med (Maywood) 2010, 235:1315-1320.

61. Pedraza-Chaverrí J, Barrera D, Hernández Pando R, Medina Campos ON, Cruz C, Murguía F. Soy protein diet ameliorates renal nitrotyrosine formation and chronic nephropathy induced by puromycin aminonucleoside. Life Sci 2004, 74:987 999. 


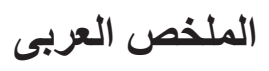

\section{دراسات هستوباثولوجية وتركيبية دقيقه للتأثثير الوقائي للايدزين و فيتامين سي على

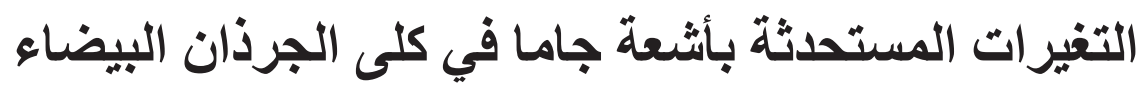

مروة صلاح'، منال عبد الحميل'، سعيد سليمان'، هدير عثمان'

'قسم علم الحيوان- كلية العلوم- جامعة بنى سويف

rالمركز القومي لبحوث وتكنولوجيا الاشعاع_هيئة الطاقة الذرية

الخلفية: العلاج الإشعاعي هو وسيلة علاجية أساسية لمجموعة واسعة من الأورام، ولكن آثاره الجانبية الحادة على

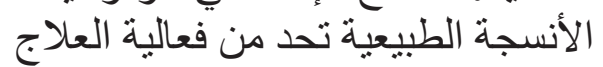

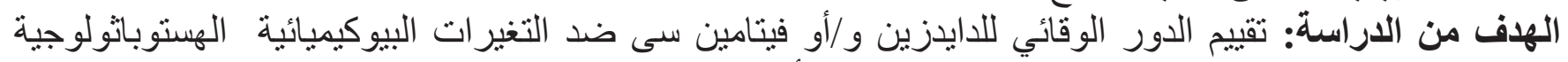

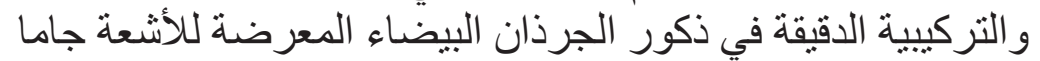

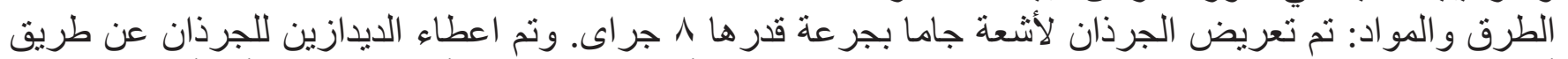

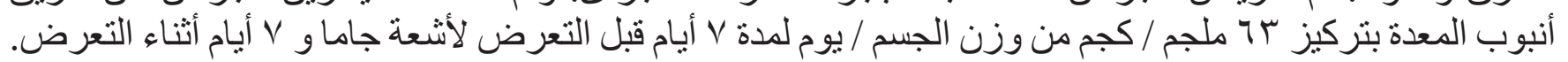

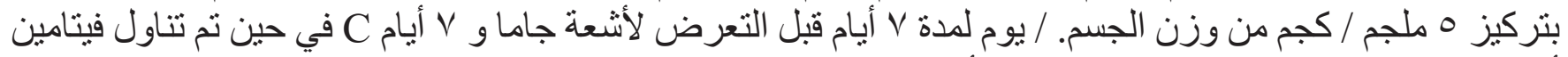

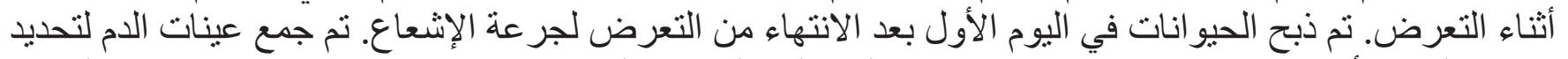

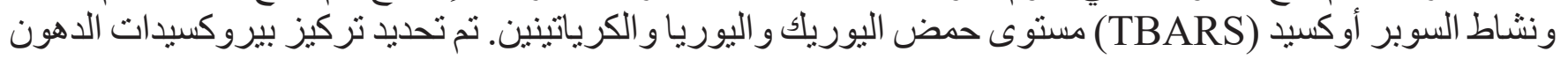

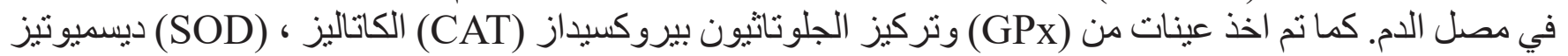

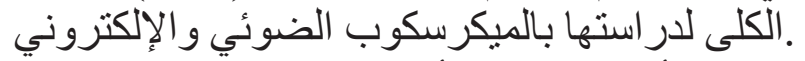

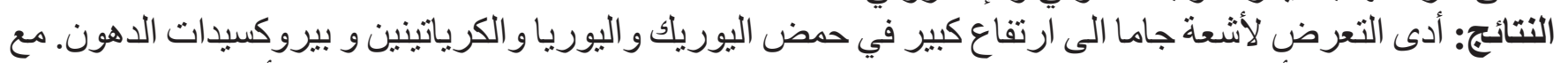

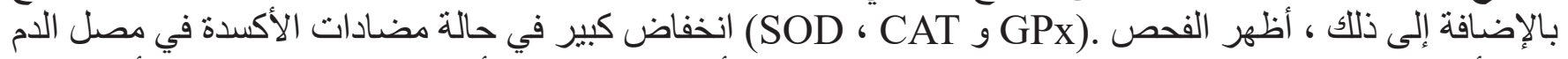

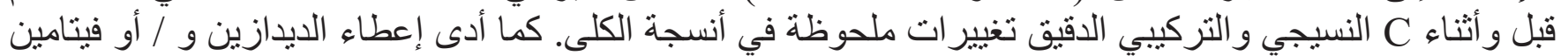

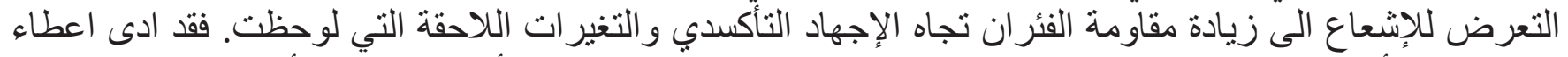

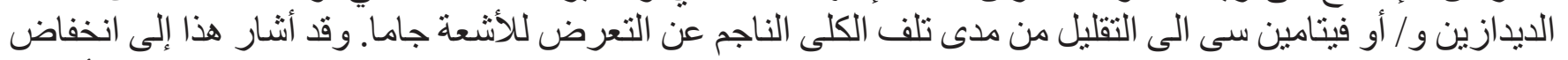

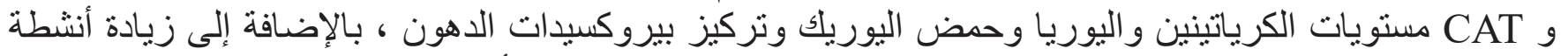

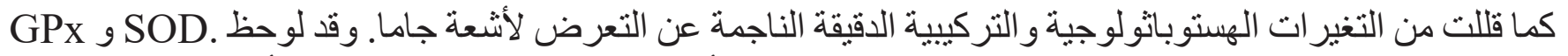

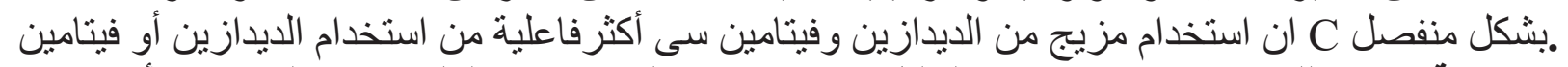

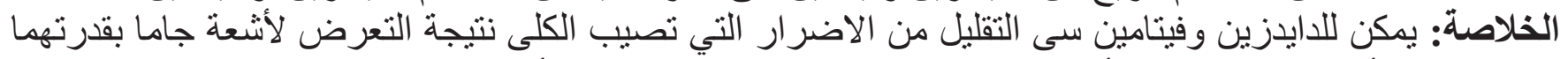

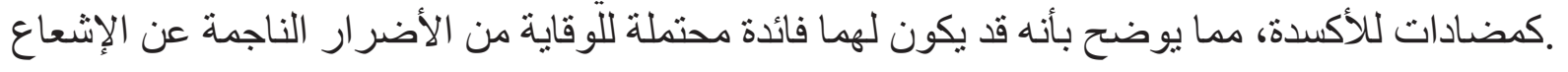

